\title{
ONLINE VISIBILITY OF PHARMACY RESEARCH IN TANZANIA: A SCIENTOMETRIC STUDY
}

\author{
EDDA TANDI LWOGA ${ }^{*}$, RAPHAEL ZOZIMUS SANGEDA², ALFRED SAID SIFE ${ }^{3}$
}

1Directorate of Library Services, Muhimbili University of Health and Allied Sciences, P. O. Box 65001, Dar Es Salaam, Tanzania, ${ }^{2}$ Department of Pharmaceutical Microbiology, School of Pharmacy, Muhimbili University of Health and Allied Sciences, P. 0. Box 65001, Dar Es Salaam, Tanzania, ${ }^{3}$ Sokoine National Agricultural Library, Sokoine University of Agriculture, P. 0. Box 3000, Morogoro, Tanzania Email: tlwoga@muhas.ac.tz

Received: 24 Apr 2017 Revised and Accepted: 13 Jul 2017

ABSTRACT

Objective: This scientometric analysis was carried out to map the online visibility of pharmacy research at Muhimbili University of Health and Allied Sciences (MUHAS) from 1981 to 2016.

Methods: Publish or Perish software was used to collect data for 33 scientists from the School of Pharmacy at MUHAS. We retrieved data on scholars' publications, citation counts, the number of authors per publication, average citations per paper, average citations per year, h-index, gindex, contemporary H-index (Hc index) and the HI-norm index.

Results: A total of 499 publications were recorded for all scholars and the most $(61 ; 12.2 \%)$ productive was 2013 . The whole study period recorded the mean relative growth rate (RGR) and doubling time (Dt) of 1.62 and 0.46 respectively. A great majority (484; 97\%) of the publications were multiple-authored with nearly one third $(157 ; 31.5 \%)$ of these being jointly contributed by six or more authors. The maximum number of citations received in a single publication was 241 . The degree of collaboration among scientists was as high as 0.97 . The top ranked pharmacy researchers showed variation in various metrics.

Conclusion: The study findings indicate a continuous growth of pharmacy publications at MUHAS since 1981. There is a high level of collaboration among scholars and many publications have made a great impact through citations.

Keywords: Bibliometric, Pharmacy, Research, Publishing, Tanzania

(C) 2017 The Authors. Published by Innovare Academic Sciences Pvt Ltd. This is an open access article under the CC BY license (http://creativecommons.org/licenses/by/4.0/) DOI: http://dx.doi.org/10.22159/ijpps.2017v9i9.19371

\section{INTRODUCTION}

In academia, tenure and career promotion are mainly based on teaching and research productivity. The old adage "publish or perish" requires that academics must produce publications for career advancement, job promotion, tenure, or fulfilling requirements for annual performance. The requirement for academics to publish their research findings is also essential for advancing theoretical foundations, professional disciplines, bring new knowledge to light, and the progress of science in general. Clinical faculty are no exception to this. Despite the fact that they are expected to maintain substantial clinical practice and teaching loads, these clinical faculty members obtain promotion and tenure based on prevailing academic norms. This means that they must face the reality of the "publish or perish" maxim. Furthermore, clinical faculty needs to communicate research findings for patients' benefits and fellow researchers who can investigate the topic more [1].

The scientometric analysis is an important method for evaluation of research performance in terms of publications productivity and their impact [2] and thus examining the relevance of a given discipline in social and scientific paradigms [3]. It focuses on quantitative and/or qualitative analysis of the research output of individual authors, departments, institutions or countries. The scientometric analysis' results can assist in ranking, promotion, awarding, budgeting, defining research priorities, policy formulation and to inform decision-making processes [4]. The number of publications produced by an individual is often regarded as a key research productivity indicator and the impact of such publications is based on the frequency of their citations. Nonetheless, a number of research performance indicators such as hindex, g-index, Hc-index and HI-norm that simultaneously consider quantitative and qualitative aspects of publications have been developed in recent years [5].

$\mathrm{H}$-index is a single-number metric that represents the impact of an author's publications. It is a combined measure of both the researcher's publications productivity and their visibility in terms of citation counts. According to Hirsch, a scholar has an index $\mathrm{h}$ if $\mathrm{h}$ of his/her $\mathrm{Np}$ publications have at least $\mathrm{h}$ citations each and the remaining (Np-h) publications have less than $\mathrm{h}$ citations each [6]. The Egghe's g-index improves the h-index by giving more weight to highly cited publications. A researcher has index $g$ if $g$ of his or her most cited publications collectively have at least $g^{2}$ citations [7]. The contemporary h-index (Hc-index) gives more weight to recent publications [8]; thus take into consideration the age of publications. The HI-norm index normalizes the number of citations for each publication through dividing the number of citations by the number of authors for that publication. This gives a better approximation of the individual author's impact in multi-authored publications [9]. One important tool that helps to obtain scholars' lists of publications and their citations is the Publish or Perish (PoP) software developed by Anne-Wil Harzing of the University of Melbourne. PoP uses Google Scholar to retrieve publications and citations and analyzes these to get metrics such as the average number of citations per year, per paper and per author; the average number of papers per year and per author; average number of authors per paper as well as $\mathrm{h}$-index and its variants [10].

In the pharmaceutical field, scientometric studies can assist to establish the research performance of individual researchers, departments and institutions. The studies can also help to establish a core list of publications and databases that can be used to support information provision [11], pharmaceutical care and pharmacy education [12]. Worldwide, there is a large number of published scientometric studies in pharmacy $[3,11,13-26]$. Such studies have determined the growth of literature, patents and citations in particular locations, author collaborative patterns, most prolific journals, institution and country-wise productivity, and major themes of research productivity. However, only a few studies employed Google Scholar to retrieve lists of publications, citation counts and other metrics $[19,22]$. For example, Mousavi, Mansouri, and Ahmadvand used several databases including Google Scholar to 
retrieve publications on the rational use of medicines in Iran [22]. Basak and Sathyanarayana used MEDLINE, Index Copernicus, IndMed and DOAJ databases and search engines such as Google, Google Scholar and Scirus to retrieve the publications and citations on community pharmacy research in India [18]. A recent longitudinal study reported that Google Scholar retrieves more publications and produces more metrics than the Web of Science and Scopus [27]. In this regard, Google Scholar is an important tool for determining the research productivity and impact of scholars in the developing world context where there is less scholarly publishing done in ISI databases.

In Tanzania, there is a scarcity of scientometric studies particularly those on medical sciences and pharmacy in particular. The few available studies in the country are those focusing on traditional medicine [28], librarianship [29], forestry [30], veterinary science [31] and grantees of International Foundation for Science [32]. Within the limits of our knowledge, no scientometric studies have been conducted in Tanzania to show the status of pharmacy research. In this regard, the present study was carried out to assess the online visibility of pharmacy research produced at the Muhimbili University of Health and Allied Sciences (MUHAS). The specific objectives of this study were to determine the growth of pharmacy literature; determine the collaborative patterns among pharmacy scientists; establish citation counts of publications; determine the research performance individual pharmacy scientists, and assess their journal preference. Pharmacy research in Tanzania commenced with the establishment of the Department of Pharmacy in the Faculty of Medicine at the University of Dar es Salaam in 1974. In 1991, this Faculty became a constituent College of the University of Dar es Salaam and the Department of Pharmacy was upgraded to become the Faculty of Pharmacy. The constituent college became the Muhimbili University College of Health Sciences (MUCHS) in 2000. In 2003, the Faculty of Pharmacy was transformed to a School of Pharmacy. At the same time, MUCHS acquired a full-fledged University status, namely Muhimbili University of Health and Allied Sciences (MUHAS). Presently, the School of Pharmacy has a total of 33 academic staff [33] making MUHAS the only university in the country with a high number of pharmacy scholars and a dedicated school dealing with pharmaceutical sciences.

\section{MATERIALS AND METHODS}

\section{Methods}

Names of all scholars who worked with the School of Pharmacy at MUHAS for different periods between 1981 and 2016 were obtained from the Dean's office. Data retrieval for all 33 pharmacy scholars was conducted between $11^{\text {th }}$ and $23^{\text {th }}$ April 2016 using the PoP software. Retrieval of online publications must be done in a short period of time because citations keep on accumulating rapidly. This study retrieved data on publications and citations that were publicly available on the Web. The names of each individual scholar and their variants were entered into the search field of PoP in order to retrieve their metrics. Search results were carefully refined to ensure that only publications of intended persons were retrieved. Duplicates were merged and ambiguous publications were verified whether they were actually belonged to the intended authors. Scholarly publications considered in this study were journal articles, books, book chapters and conference articles. Retrieved metrics were the total number of publications and citations counts, number of authors per publication, average citations per paper, average citations per year, h-index, g-index, Hc-index and the HI-norm index.

\section{RESULTS AND DISCUSSION}

\section{Publications productivity of pharmacy scholars}

A total of 499 publications including journal articles (94.4\%) were retrieved covering the period between 1981 and April 2016 (fig. 1). This number of publications is based on the "normal counting method" whereby each author receives a full count for joint publications. According to Egghe, three methods of counting the number of publications are the total or normal counting method that involves assigning every author a weight for each of the publications; the straight counting in which only the first author is assigned a weight for each publication; and the fractional counting in which every author is assigned a weight $1 / \mathrm{n}$ in an $n$-authored paper [34]. Journal articles comprise the great majority of publications simply because peer reviewed journals are the major communication channels for research findings. These 499 publications which were visible online were either published in online journals (e-journals) or they were retrieved as bibliographic information of print publications cited by online publications. Of the 33 scholars, eight of them had either not published a single scholarly article or they had not published in online journals, books or conference proceedings. The average number of publications per year was 14 with the year 2013 being the most $(61 ; 12.2 \%)$ productive (table 1). It should be noted that these publication data were extracted in April 2016; hence it is likely that the total publication productivity for the year 2016 was incomplete.

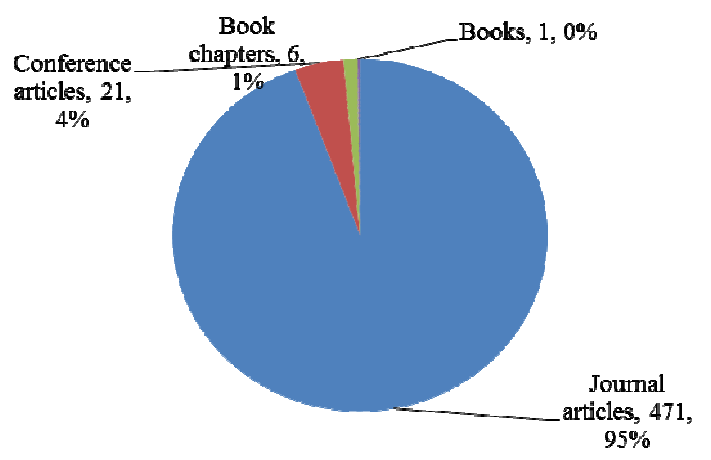

Fig. 1: Types of publications retrieved

The growth of publications was also analyzed on the basis of the relative growth rate (RGR) using the formula RGR $=\left(\operatorname{lnN}_{2}-\operatorname{lnN}_{1}\right) /\left(t_{2}-t_{1}\right)$ where N2 and $\mathrm{N} 1$ are the cumulative numbers of publications in the years $t_{2}$ and $t_{1}$. RGR is the increase in the number of publications per unit of time. Study findings in table 1 indicate that RGR had increased from 0.00 (1981) to 4.13 (2016) with some fluctuations in the years in-between. Similarly, the mean RGR for the block periods of five years increased from 0.41 (1981-1985) to 2.53 (2011-2016). Doubling time (Dt) which is the period of time required for publications to double was calculated using the formula $\mathrm{Dt}=0.693 / \mathrm{RGR}$. Dt is related to RGR in that if the number of articles double then the difference between the logarithms of numbers at the beginning and end of that period is 693[35]. In this study, Dt decreased from 1.00 (1983) to 0.17 (2016) with some fluctuations inbetween. Likewise, the mean Dt for the block periods of five years decreased from 0.79 (1986-1990) to 0.30 (2011-2016). The whole study period recorded the mean RGR and Dt of 1.62 and 0.46 respectively. Generally, these findings indicate that the publication productivity of pharmacy scholars at MUHAS had increased gradually over the period of $36 \mathrm{y}$.

\section{Collaboration patterns among pharmacy scholars}

The study findings show a domination of multiple authorships (484; $96.9 \%)$ in pharmacy research at MUHAS. Nearly a third (157; $31.5 \%$ ) of the publications was jointly contributed by six or more authors whereas only $15(3 \%)$ publications had single authors (table 2 ). The average degree of collaboration computed as the ratio of collaborative publications to the total number of publications [36] was as high as 0.97. Some years had recorded a maximum collaboration coefficient of 1.0. This suggests that collaboration in pharmacy research at MUHAS is very high. Similar findings had been reported in other studies in pharmacy [37].

One reason for this collaborative trend might be the increased interdisciplinary characteristics of modern science which calls for sharing of expertise. In addition, funding agencies often prefer research collaboration as part of their funding conditions. In universities, collaboration in research is an important method for mentoring graduate students and young researchers. 
Table 1: Publications productivity of pharmacy scholars

\begin{tabular}{|c|c|c|c|c|c|c|c|c|}
\hline Year & No of publications & Cumulative publications & $\ln N_{1}$ & $\ln N_{2}$ & RGR & Mean RGR & Dt & Mean Dt \\
\hline 1981 & 0 & 0 & 0.00 & 0.00 & 0.00 & \multirow[t]{5}{*}{0.41} & 0.00 & \multirow[t]{5}{*}{0.60} \\
\hline 1982 & 1 & 1 & 0.00 & 0.00 & 0.00 & & 0.00 & \\
\hline 1983 & 1 & 2 & 0.00 & 0.69 & 0.69 & & 1.00 & \\
\hline 1984 & 0 & 2 & 0.00 & 0.69 & 0.69 & & 1.00 & \\
\hline 1985 & 0 & 2 & 0.00 & 0.69 & 0.69 & & 1.00 & \\
\hline 1986 & 0 & 2 & 0.00 & 0.69 & 0.69 & \multirow[t]{5}{*}{0.93} & 1.00 & \multirow[t]{5}{*}{0.79} \\
\hline 1987 & 0 & 2 & 0.00 & 0.69 & 0.69 & & 1.00 & \\
\hline 1988 & 1 & 3 & 0.00 & 1.10 & 1.10 & & 0.63 & \\
\hline 1989 & 2 & 5 & 0.69 & 1.61 & 0.92 & & 0.76 & \\
\hline 1990 & 2 & 7 & 0.69 & 1.95 & 1.25 & & 0.55 & \\
\hline 1991 & 2 & 9 & 0.69 & 2.20 & 1.50 & \multirow[t]{5}{*}{1.75} & 0.46 & \multirow[t]{5}{*}{0.41} \\
\hline 1992 & 0 & 9 & 0.00 & 2.20 & 2.20 & & 0.32 & \\
\hline 1993 & 3 & 12 & 1.10 & 2.48 & 1.39 & & 0.50 & \\
\hline 1994 & 2 & 14 & 0.69 & 2.64 & 1.95 & & 0.36 & \\
\hline 1995 & 3 & 17 & 1.10 & 2.83 & 1.73 & & 0.40 & \\
\hline 1996 & 3 & 20 & 1.10 & 3.00 & 1.90 & \multirow[t]{5}{*}{0.78} & 0.37 & \multirow[t]{5}{*}{0.40} \\
\hline 1997 & 3 & 23 & 1.10 & 3.14 & 2.04 & & 0.34 & \\
\hline 1998 & 7 & 30 & 1.95 & 3.40 & 1.46 & & 0.48 & \\
\hline 1999 & 6 & 36 & 1.79 & 3.58 & 1.79 & & 0.39 & \\
\hline 2000 & 8 & 44 & 2.08 & 3.78 & 1.70 & & 0.41 & \\
\hline 2001 & 9 & 53 & 2.20 & 3.97 & 1.77 & \multirow[t]{5}{*}{1.83} & 0.39 & \multirow[t]{5}{*}{0.39} \\
\hline 2002 & 15 & 68 & 2.71 & 4.22 & 1.51 & & 0.46 & \\
\hline 2003 & 19 & 87 & 2.94 & 4.47 & 1.52 & & 0.46 & \\
\hline 2004 & 13 & 100 & 2.56 & 4.61 & 2.04 & & 0.34 & \\
\hline 2005 & 11 & 111 & 2.40 & 4.71 & 2.31 & & 0.30 & \\
\hline 2006 & 26 & 137 & 3.26 & 4.92 & 1.66 & \multirow[t]{5}{*}{1.91} & 0.42 & \multirow[t]{5}{*}{0.38} \\
\hline 2007 & 50 & 187 & 3.91 & 5.23 & 1.32 & & 0.53 & \\
\hline 2008 & 20 & 207 & 3.00 & 5.33 & 2.34 & & 0.30 & \\
\hline 2009 & 32 & 239 & 3.47 & 5.48 & 2.01 & & 0.34 & \\
\hline 2010 & 29 & 268 & 3.37 & 5.59 & 2.22 & & 0.31 & \\
\hline 2011 & 37 & 305 & 3.61 & 5.72 & 2.11 & \multirow[t]{7}{*}{2.53} & 0.33 & \multirow[t]{7}{*}{0.30} \\
\hline 2012 & 39 & 344 & 3.66 & 5.84 & 2.18 & & 0.32 & \\
\hline 2013 & 61 & 405 & 4.11 & 6.00 & 1.89 & & 0.37 & \\
\hline 2014 & 52 & 457 & 3.95 & 6.12 & 2.17 & & 0.32 & \\
\hline 2015 & 34 & 491 & 3.53 & 6.20 & 2.67 & & 0.26 & \\
\hline \multirow[t]{2}{*}{2016} & 8 & 499 & 2.08 & 6.21 & 4.13 & & 0.17 & \\
\hline & 499 & & & & 1.62 & & 0.46 & \\
\hline
\end{tabular}

RGR: a measure of the increase in number of publications with time, Dt: the time required for the number of articles to double, N2 and N1: the cumulative publications in two years.

\section{Citations trends of individual publications}

The top 10 most cited pharmacy publications from MUHAS had received an average of 123.2 citations each. The top cited paper was "Chemical composition and antimicrobial activity of the essential oils of four Ocimum species growing in Tanzania, jointly authored by Runyoro, D., Ngassapa, O., Vagionas, K., Aligiannis, N., Graikou, K. and Chinou, I. This article was published in 2010 and receives 17.3 citations/year (table 3). It was observed that all these top 10 papers are having multiple authors supporting the fact that citation counts of publications depend on many factors including the number of authors, accessibility of journals where articles are published, the age of the publication, the quality of the publication, the size of the scientific community, and the topic which ones publishes [38].

\section{Productivity and scholarly impact of individual scholars}

The study findings in table 4 indicate various performance metrics of the top 10 ranked pharmacy scholars at MUHAS. These had together contributed two-thirds $(331 ; 66.3 \%$ ) of all publications giving an average of 33 publications per scholar. These findings support the Lotka's Law of scientific work that many authors tend to publish a relatively small number of articles, with the large proportion of publications being made by few individuals [39]. These pharmacy scholars also showed variation in their productivity and impact since no single scholar maintained the same rank in all metrics. Hence, it can be argued that research performance cannot easily be determined using a single indicator.

Professor A. R. Kamuhabwa was the most prolific author (68 publications) and he had the highest number of citation (1330 citations) and yearly impact (73.89 cites per year). He also had the highest hindex (19), g-index (35), Hc-index (13) and HI-norm index (11). E. A. Kaale ( 56 publications) ranked the second in terms of publications followed by 0. M. S. Minzi (49 publications). With regard to citation counts, 0 . Ngassapa ranked the second ( 959 citations) followed by Kaale (682 citations). These findings also show that some of the top ranked scholars in terms of publications had fewer citations.

This supports the argument that individual's citation counts depend on factors other than the number of publications. Minzi ranked the second in yearly impact (46.43 cites per year) followed by E. Ngaimisi (41.14 cites per year). When taking into account the number of cites given to each individual publication, Ngassapa ranked the first followed by D. K. B. Runyoro and W. M. Kalala with 33.07, 28.58 and 26.57 cites per paper respectively. Kaale had the second highest hindex of 17 followed by Ngassapa with h-index of 16. Ngassapa had the second highest g-index (29) followed by Kaale (g-index 25).

In terms of newly published works, Kaale and Runyoro ranked the second with Hc-index 12 each and the third place was shared by Ngassapa and Ngaimisi each having Hc-index of 10. Considering the HI norm-index which evaluates the effects of co-authorship, Ngassapa ranked the second with index of 9 followed by Minzi with index of 8. Overall, Kamuhabwa ranked the first followed by Ngassapa and Minzi. It should be emphasized that ranking of researchers in this study was based on publications and citations that were available online covering the period of 1981-2016. It is possible that some senior scholars could rank differently if their work was evaluated based on their carrier or if their offline scholarly works were retrieved. 
Table 2: Collaboration patterns among pharmacy scholars

\begin{tabular}{|c|c|c|c|c|c|c|c|c|}
\hline \multirow[t]{2}{*}{ Year } & \multicolumn{7}{|c|}{ Number of publication by number of authors } & \multirow{2}{*}{$\begin{array}{l}\text { Collaboration } \\
\text { coefficient }\end{array}$} \\
\hline & $\begin{array}{l}\text { Single } \\
\text { author }\end{array}$ & $\begin{array}{l}\text { Two } \\
\text { authors }\end{array}$ & $\begin{array}{l}\text { Three } \\
\text { authors }\end{array}$ & $\begin{array}{l}\text { Four } \\
\text { authors }\end{array}$ & $\begin{array}{l}\text { Five } \\
\text { authors }\end{array}$ & $\begin{array}{l}\text { Six or more } \\
\text { authors }\end{array}$ & Total & \\
\hline 1981 & 0 & 0 & 0 & 0 & 0 & 0 & 0 & 0.00 \\
\hline 1982 & 0 & 0 & 0 & 1 & 0 & 0 & 1 & 1.00 \\
\hline 1983 & 0 & 0 & 0 & 0 & 1 & 0 & 1 & 1.00 \\
\hline 1984 & 0 & 0 & 0 & 0 & 0 & 0 & 0 & 0.00 \\
\hline 1985 & 0 & 0 & 0 & 0 & 0 & 0 & 0 & 0.00 \\
\hline 1986 & 0 & 0 & 0 & 0 & 0 & 0 & 0 & 0.00 \\
\hline 1987 & 0 & 0 & 0 & 0 & 0 & 0 & 0 & 0.00 \\
\hline 1988 & 0 & 0 & 0 & 1 & 0 & 0 & 1 & 1.00 \\
\hline 1989 & 0 & 1 & 0 & 0 & 1 & 0 & 2 & 1.00 \\
\hline 1990 & 0 & 0 & 1 & 0 & 0 & 1 & 2 & 0.50 \\
\hline 1991 & 1 & 0 & 0 & 0 & 1 & 0 & 2 & 0.50 \\
\hline 1992 & 0 & 0 & 0 & 0 & 0 & 0 & 0 & 0.00 \\
\hline 1993 & 0 & 0 & 0 & 1 & 1 & 1 & 3 & 0.67 \\
\hline 1994 & 0 & 0 & 1 & 1 & 0 & 0 & 2 & 1.00 \\
\hline 1995 & 0 & 1 & 0 & 1 & 1 & 0 & 3 & 1.00 \\
\hline 1996 & 0 & 0 & 0 & 2 & 0 & 1 & 3 & 0.67 \\
\hline 1997 & 0 & 0 & 0 & 0 & 1 & 2 & 3 & 0.33 \\
\hline 1998 & 0 & 0 & 0 & 0 & 1 & 6 & 7 & 0.14 \\
\hline 1999 & 0 & 0 & 0 & 1 & 3 & 2 & 6 & 0.67 \\
\hline 2000 & 0 & 0 & 5 & 0 & 3 & 0 & 8 & 1.00 \\
\hline 2001 & 0 & 2 & 1 & 2 & 3 & 0 & 8 & 1.00 \\
\hline 2002 & 1 & 0 & 2 & 3 & 2 & 7 & 15 & 0.47 \\
\hline 2003 & 0 & 0 & 1 & 3 & 5 & 9 & 18 & 0.47 \\
\hline 2004 & 0 & 1 & 1 & 4 & 3 & 4 & 13 & 0.69 \\
\hline 2005 & 0 & 0 & 1 & 2 & 1 & 7 & 11 & 0.36 \\
\hline 2006 & 0 & 1 & 7 & 9 & 5 & 4 & 26 & 0.85 \\
\hline 2007 & 3 & 4 & 10 & 8 & 13 & 12 & 50 & 0.70 \\
\hline 2008 & 1 & 4 & 4 & 3 & 2 & 6 & 20 & 0.65 \\
\hline 2009 & 4 & 6 & 6 & 4 & 3 & 9 & 32 & 0.59 \\
\hline 2010 & 0 & 6 & 7 & 2 & 3 & 11 & 29 & 0.62 \\
\hline 2011 & 0 & 10 & 8 & 2 & 3 & 14 & 37 & 0.62 \\
\hline 2012 & 3 & 3 & 6 & 4 & 5 & 18 & 39 & 0.46 \\
\hline 2013 & 0 & 11 & 3 & 12 & 12 & 24 & 62 & 0.62 \\
\hline 2014 & 1 & 12 & 12 & 6 & 9 & 12 & 52 & 0.75 \\
\hline 2015 & 1 & 8 & 5 & 8 & 10 & 3 & 35 & 0.88 \\
\hline 2016 & 0 & 0 & 0 & 2 & 2 & 4 & 8 & 0.50 \\
\hline Total & 15 & 70 & 81 & 82 & 94 & 157 & 499 & \\
\hline Percent & 3.0 & 14.0 & 16.2 & 16.4 & 18.8 & 31.5 & 100 & \\
\hline
\end{tabular}

Collaboration coefficient: the ratio of collaborative publications to the total number of publications

Highly cited journal articles

\begin{tabular}{|c|c|c|c|}
\hline No & Title of article & Citations & Cites/year \\
\hline 6 & $\begin{array}{l}\text { Runyoro, D., Ngassapa, O., Vagionas, K., Aligiannis, N., Graikou, K. and Chinou, I., 2010. Chemical composition and anti- } \\
\text { microbial activity of the essential oils of four Ocimum species growing in Tanzania. Food Chemistry, 119(1), pp.311-316. }\end{array}$ & 104 & 17.3 \\
\hline 5 & $\begin{array}{l}\text { Geldmacher, C., Currier, J. R., Herrmann, E., Haule, A., Kuta, E., McCutchan, F., Njovu, L., Geis, S., Hoffmann, O., } \\
\text { Maboko, L. and Williamson, C., 2007. CD8 T-cell recognition of multiple epitopes within specific Gag regions is } \\
\text { associated with maintenance of a low steady-state viremia in human immunodeficiency virus type } 1 \text {-seropositive } \\
\text { patients. Journal of Virology, 81(5), pp.2440-2448. }\end{array}$ & 125 & 13.9 \\
\hline 3 & $\begin{array}{l}\text { Runyoro, D. K., Matee, M. I., Ngassapa, O. D., Joseph, C. C. and Mbwambo, Z. H., 2006. Screening of Tanzanian } \\
\text { medicinal plants for anti-Candida activity. BMC Complementary and Alternative Medicine, 6(1), p.1. }\end{array}$ & 136 & 13.6 \\
\hline 1 & $\begin{array}{l}\text { Kinget, R., Kalala, W., Vervoort, L. and Van den Mooter, G., 1998. Colonic drug targeting. Journal of Drug Targeting, } \\
6(2), \text { pp.129-149. }\end{array}$ & 241 & 13.4 \\
\hline 9 & $\begin{array}{l}\text { Maregesi, S. M., Pieters, L., Ngassapa, O. D., Apers, S., Vingerhoets, R., Cos, P., Berghe, D. A. V. and Vlietinck, A. J., } \\
\text { 2008. Screening of some Tanzanian medicinal plants from Bunda district for antibacterial, antifungal and antiviral } \\
\text { activities. Journal of Ethnopharmacology, 119(1), pp.58-66. }\end{array}$ & 88 & 11.0 \\
\hline 2 & $\begin{array}{l}\text { Delaey, E., van Laar, F., De Vos, D., Kamuhabwa, A., Jacobs, P. and de Witte, P., 2000. A comparative study of the } \\
\text { photosensitizing characteristics of some cyanine dyes. Journal of Photochemistry and Photobiology B: Biology, } \\
\text { 55(1), pp.27-36. }\end{array}$ & 151 & 9.4 \\
\hline 4 & $\begin{array}{l}\text { D'Hallewin, M. A., Kamuhabwa, A. R., Roskams, T., De Witte, P. A. M. and Baert, L., } 2002 \text {. Hypericin-based } \\
\text { fluorescence diagnosis of bladder carcinoma. BJU International, 89(7), pp.760-763. }\end{array}$ & 131 & 9.4 \\
\hline 10 & $\begin{array}{l}\text { Vagionas, K., Graikou, K., Ngassapa, O., Runyoro, D. and Chinou, I., 2007. Composition and antimicrobial activity of } \\
\text { the essential oils of three Satureja species growing in Tanzania. Food Chemistry, 103(2), pp.319-324. }\end{array}$ & 79 & 8.8 \\
\hline 7 & $\begin{array}{l}\text { Derycke, A. S., Kamuhabwa, A., Gijsens, A., Roskams, T., De Vos, D., Kasran, A., Huwyler, J., Missiaen, L. and de Witte, } \\
\text { P. A., 2004. Transferrin-conjugated liposome targeting of photosensitizer AlPcS4 to rat bladder carcinoma cells. } \\
\text { Journal of the National Cancer Institute, } 96(21) \text {, pp.1620-1630. }\end{array}$ & 89 & 7.4 \\
\hline 8 & $\begin{array}{l}\text { Kamuhabwa, A. R., Agostinis, P., D'Hallewin, M. A., Kasran, A. and de Witte, P. A., 1999. Photodynamic activity of } \\
\text { hypericin in human urinary bladder carcinoma cells. Anticancer Research, 20(4), pp.2579-2584 }\end{array}$ & 88 & 5.2 \\
\hline
\end{tabular}

Cites/year: the average number of citations per year and it is calculated by dividing the total number of citations by the age of an article. It provides

a fairer comparison for articles published in different years. 
Table 4: Ranked list of prolific pharmacy scholars

\begin{tabular}{|c|c|c|c|c|c|c|c|c|c|}
\hline Author name & $\begin{array}{l}\text { No. of } \\
\text { publications }\end{array}$ & $\begin{array}{l}\text { No. of } \\
\text { citations }\end{array}$ & Cites/year & Cites/paper & $\begin{array}{l}\text { H- } \\
\text { index }\end{array}$ & $\begin{array}{l}\text { G- } \\
\text { index }\end{array}$ & $\begin{array}{l}\text { HC- } \\
\text { index }\end{array}$ & $\begin{array}{l}\text { HI- } \\
\text { norm }\end{array}$ & $\begin{array}{l}\text { Average } \\
\text { position }\end{array}$ \\
\hline A. R. & $68(1)$ & $1330(1)$ & $73.89(1)$ & $19.85(4)$ & $19(1)$ & $35(1)$ & $13(1)$ & $11(1)$ & 1 \\
\hline \multicolumn{10}{|l|}{ Kamuhabwa } \\
\hline O. Ngassapa & $28(6)$ & $959(2)$ & $35.52(4)$ & 33.07 (1) & $16(3)$ & $29(2)$ & $10(3)$ & $9(2)$ & 2 \\
\hline O. M. S. Minzi & $49(3)$ & $650(4)$ & $46.43(2)$ & $13.27(10)$ & $15(4)$ & $24(4)$ & $12(2)$ & $8(3)$ & 3 \\
\hline E. A. Kaale & $56(2)$ & $682(3)$ & $18.43(7)$ & $11.76(11)$ & $17(2)$ & $25(3)$ & $12(2)$ & $9(2)$ & 4 \\
\hline D. K. B. & $19(9)$ & $543(5)$ & $15.97(9)$ & $28.58(2)$ & $9(5)$ & $19(5)$ & $7(5)$ & $6(4)$ & 5 \\
\hline \multicolumn{10}{|l|}{ Runyoro } \\
\hline E. Ngaimisi & $21(8)$ & $288(8)$ & $41.14(3)$ & $13.71(9)$ & $9(5)$ & $16(7)$ & $10(3)$ & $4(5)$ & 6 \\
\hline S. M. Maregesi & $19(10)$ & 291(7) & $29.10(5)$ & $15.32(6)$ & $7(7)$ & $17(6)$ & $7(5)$ & $4(5)$ & 7 \\
\hline K. D. & $42(4)$ & 265 (9) & $22.08(6)$ & $6.31(12)$ & $9(5)$ & $15(8)$ & $8(4)$ & $6(4)$ & 8 \\
\hline \multicolumn{10}{|l|}{ Mwambete } \\
\hline W. M. Kalala & $14(15)$ & $372(6)$ & $17.71(8)$ & $26.57(3)$ & $6(8)$ & $14(9)$ & $6(6)$ & $4(5)$ & 9 \\
\hline A. F. Haule & $15(13)$ & $243(10)$ & $14.29(10)$ & $16.20(5)$ & $7(7)$ & $15(8)$ & $5(7)$ & $4(5)$ & 10 \\
\hline
\end{tabular}

Note: Number in parentheses is the scholars rank on that measure, Cites/year: the average number of citations per year and it is calculated by dividing the total number of citations by the age of an article, Cites/paper: the average number of citations per paper, $\mathrm{H}$-index: The Publish or Perish program calculates the h-index (Hirsch-index) and its variants (i.e. G-index, Hc-index, HI-norm and others) based on the scholar's most cited papers and the number of citations that they have received in other publications.

The G-index: improves the h-index by giving more weight to highly cited publications

The contemporary h-index (Hc-index): adds an age-related weighting to each cited article, giving less weight to older articles.

The HI-norm index divides the number of citations by the number of authors for that publication.

\section{Journal preference}

The distribution of articles in journals revealed that during the period between 1981 and 2016, pharmacy scholars at MUHAS published their research findings in 123 different journals with 23 journals having at least 5 articles each. The East and Central African Journal of Pharmaceutical Sciences had 32 articles followed by the Tanzania Medical Journal (20 articles) (table 5). Although the findings indicate that these scholars had been publishing their research findings in a wide range of international journals, there are only three local journals in the top 23 journals that these scholars published their research findings.

This means that there is a scarcity of relevant journals in the country for these researchers to publish their articles.

\section{Subject-wise distribution of publications}

The subject-wise break-up of 499 publications based on broad subject categories shows nearly equal distributions in pharmacology (19\%), Pharmaceutics (15.4\%), pharmacognosy (14.6\%) and medicinal chemistry (14.2\%) (table 6). The "other" subject category comprised $22.6 \%$ of all publications.

Velmurugan and Radhakrishnan (2015) also reported that more than 65 percent of articles were from pharmacology research followed by plant sciences and chemistry. Findings of the present study are very significant for evidence-based policy development on how to prioritize research interests in the field of pharmacy.

Table 5: Journal-wise distribution of publications

\begin{tabular}{lll}
\hline No & Journal & $\begin{array}{l}\text { Number of } \\
\text { articles }\end{array}$ \\
\hline 1 & East and Central African Journal of Pharmaceutical Sciences & 32 \\
2 & Tanzania Medical Journal & 20 \\
3 & Journal of Ethnopharmacology & 11 \\
4 & Journal of Planar Chromatography-Modern TLC & 10 \\
5 & Malaria Journal & 10 \\
6 & Food Chemistry & 8 \\
7 & African Health Science & 7 \\
8 & East African Journal of Public Health & 7 \\
9 & Electrophoresis & 7 \\
10 & Journal of Chromatography A & 7 \\
11 & PlantaMedica & 7 \\
12 & Plos One & 7 \\
13 & Tropical Medicine and International Health & 7 \\
14 & Drug, Healthcare and Patient Safety & 6 \\
15 & International Journal of Oncology & 6 \\
16 & Journal of Chromatography B & 6 \\
17 & Journal of Natural Products & 6 \\
18 & Journal of Pharmaceutical and Biomedical Analysis & 6 \\
19 & Tropical Journal of Pharmaceutical Research & 6 \\
20 & International Journal of Pharmacy Practice & 5 \\
21 & Journal of Public Health & 5 \\
22 & Journal of the International Association of Physicians in AIDS Care & 5 \\
23 & Tanzania Journal of Health Research & 5 \\
Total & & 196 \\
\hline
\end{tabular}


Table 6: Subject-wise distribution of publications

\begin{tabular}{lll}
\hline Subject & Number of publications & Percentages \\
\hline Bioinformatics & 4 & 0.8 \\
Education & 6 & 1.2 \\
Microbiology & 60 & 12.0 \\
Medicinal chemistry & 71 & 14.2 \\
Pharmacognosy & 73 & 14.6 \\
Pharmaceutics & 77 & 15.4 \\
Pharmacology & 95 & 19.0 \\
Others & 113 & 22.6 \\
Total & 499 & 100.0 \\
\hline
\end{tabular}

\section{CONCLUSION}

The study findings indicate continuous growth of pharmacy publications since 1981 with journal articles being the most prominent type of publications. There was a high level of collaboration among scholars as most publications had multiple authors. Many publications had been cited by other scientists, suggesting a greater research impact. Although pharmacy scholars have published their articles in 123 different journals, about $42 \%$ of the articles were published only in 23 journals and only a few articles were published Tanzanian journals. These study findings have several implications. Firstly, the study findings call for scholars to publish their papers in journals that can be accessed easily in order to increase the impact of research.

These include online journals and those following the open access model. Secondly, since research has proved to be highly collaborative in nature, it is important for institutions to consider giving each author a full credit for each publication irrespective of their position in the byline. Thirdly, journals should adopt open access and online publishing approaches to enhance their online visibility and citation rates. Lastly, it is important for institutions to consider various metrics when evaluating the research productivity of individuals.

This study has some limitations. This study focused on publications and citations that were available online. This means that publications and citations that were not available on the web were not retrieved considering that some senior scholars had previously published their articles in print journals or their articles are cited in print publications. This study only focused to pharmacy researchers from one University in Tanzania. Future studies should, therefore, cover all pharmacy researchers in the country or across the region in order to determine if the findings from this study are unique or if other scientometric studies in pharmacy show similar patterns.

\section{AUTHOR CONTRIBUTION}

Edda Tandi Lwoga: Conducted literature review for this paper, and developed introduction section of the paper together with the discussion of the study findings.

Raphael Sangeda: Conducted analysis on the subject-wise distribution of publications, provided a description of the background information of the School of Pharmacy field, and participated in writing the paper.

Alfred Said Sife: Developed the methodology section, collected and analyzed data and participated in writing the paper.

\section{CONFLICT OF INTERESTS}

Declared none

\section{REFERENCES}

1. Sreeja PA, Arya US, Kumar AS, Swathy S. Scientific writing as an art: an overview. Int J Curr Pharm Res 2016;8:2-5.

2. Zyoud SH, Al-jabi SW, Sweileh WM. Scientific publications from the Arab world in leading journals of integrative and complementary medicine: a bibliometric analysis. BMC Complement Altern Med 2015;15:1-10.

3. Lopez-munoz F, Srinivasan V, Gutierrez-soriano A, Shen WW, Rubio G, Alamo C. A bibliometric analysis of scientific research on atypical antipsychotic drugs in India during 1998-2013. Mol Med Chem 2016;23:1-13.

4. Abolghassemi Fakhree MA, Jouyban A. Scientometric analysis of the major Iranian medical universities. Scientometrics 2011;87:205-20.

5. Van Leeuwen TN, Visser MS, Moed HF, Nederhof TJ, Van Raan AFJ. The holy grail of science policy: Exploring and combining bibliometric tools in search of scientific excellence. Scientometrics 2003. p. 257-80.

6. Hirsch J. An index to quantify an individual's scientific research output. Proc Natl Acad Sci USA 2005;102:16569-72.

7. Egghe L. Theory and practice of the g-index. Scientometrics 2006;69:131-52.

8. Sidiropoulos A, Katsaros D, Manolopoulos Y. Generalized hirsch h-index for disclosing latent facts in citation networks. Scientometrics 2007;72:253-80.

9. Braun T, Glänzel W, Schubert A. A Hirsch-type index for journals. Scientometrics 2006;69:169-73.

10. Harzing A. The publish or perish book: A guide to the software; 2011.

11. Barrett A, Helwig M, Neves K. Mapping the literature of hospital pharmacy. Bull Med Libr Assoc 2016;104:118-24.

12. Tanjung HR, Nasution ES. The development of top 200 prescribed drugs in community pharmacies at Medan city as learning tools. Asian J Pharm Clin Res 2017;10:9-11.

13. Ahmadian S, Fakhree MA, Amini A, Jouyban A. Analysis of pharmacy related publications, H-indices, and patents of 102 countries. Pharm Sci 2013;19:53-8.

14. Bordons M, Aparicio J, Costas R. Trends in the collaborative structure of the Spanish pharmacological scientific production and its influence over research impact. Proc 17th Int Conf Sci Technol Indic 2012;1:142-54.

15. Alhaider I, Mueen Ahmed KK, Gupta BM. Pharmaceutical research in the kingdom of Saudi Arabia: a scientometric analysis during 2001-2010. Saudi Pharm J 2013;23:215-22.

16. Atkinson J. A bibliometric analysis of the scientific output of EU pharmacy departments. Pharmacy 2013;1:172-80.

17. Babar ZUD, Scahill SL, Akhlaq M, Garg S. A bibliometric review of pharmacy education literature in the context of low-to middle-income countries. Curr Pharm Teach Learn 2013;5:218-32.

18. Basak SC, Sathyanarayana D. Community pharmacy based research activity in India: a bibliometric study of the past ten years. South Med Rev 2010;3:7-10.

19. Daughton CG. Pharmaceuticals and the Environment (PiE): evolution and impact of the published literature revealed by bibliometric analysis. Sci Total Environ 2016;562:391-426.

20. Gorraiz J, Schloegl C. A bibliometric analysis of pharmacology and pharmacy journals: scopus versus web of science. J Inf Sci 2008;34:715-25.

21. Gupta R, Ahmed KM, Gupta B. High productivity pharmaceutical organizations in India: A study of their performance during 2008-12. J Young Pharm 2014;6:4-13.

22. Mousavi S, Mansouri A, Ahmadvand A. A bibliometric study of publication patterns in the rational use of medicines in Iran. Pharm Pract 2013;11:38-43.

23. Plotnikova T, Rake B. Collaboration in pharmaceutical research: Exploration of country-level determinants. Scientometrics 2014;98:1173-202. 
24. Rafols I, Hopkins MM, Hoekman J, Siepel J, Hare AO, Perianesrodríguez A, et al. Big pharma, little science? A bibliometric perspective on big pharma's $\mathrm{R}$ and $\mathrm{D}$ decline. Technol Forecast Soc Chang 2014;81:22-38.

25. Sweileh WM, Zyoud SH, Al-jabi SW, Sawalha AF. Public, environmental, and occupational health research activity in Arab countries: bibliometric, citation, and collaboration analysis. Arch Public Health 2015;73:1-12.

26. Velmurugan C. Scientometric analysis: annals of library and information studies publications output during 2007-2012. Int J Library Information Sci 2013;3:58-65.

27. Harzing A. Google scholar, scopus and the web of science: a longitudinal and cross-disciplinary comparison. Scientometrics 2016;106:787-804

28. Lwoga E, Sife A. Mapping the research productivity and scholarly impact of the traditional medicine scholars in tanzania: a scientometric analysis. Int J Digital Library Services 2013;3:38-52.

29. Sife A, Lwoga E. Publication productivity and scholarly impact of academic librarians in Tanzania. New Library World 2014;115:527-41.

30. Sife ASA, Bernard R, Ernest EE, Benard R. Research productivity and scholarly impact of forestry researchers at Sokoine University of agriculture: a bibliometric analysis. J Contin Educ Ext 2013;4:261-78.
31. Sife A, Bernard RB. Scientometric portrait of Prof. Rudovick R. Kazwala: A public health veterinarian. Int J Libr Inf Stud 2016;6:63-76.

32. Gaillard J, Zink A, Tullberg A. Strengthening science capacity in Tanzania: an impact analysis of IFS support. Stolkhom: International Foundation for Science; 2002.

33. MUHAS. School of Pharmacy at MUHAS; 2016. Available from: www.sop.muhas.ac.tz. [Last accessed on 20 Mar 2017]

34. Egghe L. On the influence of growth on obsolescence. Scientometrics 1993;27:195-214.

35. Mahapatra G. Correlation between growth of publications and citations: a study based on growth curves. ALIS 1994;41:8-12.

36. Subramanyan K. Bibliometric studies of research collaboration: a review. J Inf Sci 1983;6:33-8.

37. Velmurugan C, Radhakrishnan N. A scientometric analysis of research papers published on pharmacognosy as reflected in the web of science. Adv Pharmacogn Phytomed 2015;1:27-40.

38. Bornmann L, Daniel HD. What do citation counts measure? a review of studies on citing behavior. J Doc 2008;64:45-80.

39. Lotka A. The frequency distribution of scientific productivity. J Washingt Acad Sci 1926;16:317-23.

\section{How to cite this article}

- Rana Obaidat, Bashar Al-Taani, Hanan AL-Quraan. Effect of selected polymers on dissolution and stabilization of amorphous form of meloxicam. Int J Pharm Pharm Sci 2017;9(9):72-78. 